\title{
ADENTRANDO O OLHO DA TEMPESTADE: OS DESAFIOS EM PEACEBUILDING NA ESFERA INTERNACIONAL
}

\section{Entering the Eye of the Storm: the challenges in Peacebuilding in the international sphere}

\author{
Resenha de LEDERACH, John Paul. JENNER, Janice Moomaw. (Ed.) A Handbook of \\ International Peacebuilding: Into the Eye of the Storm. Jossey-Bass a Wiley Imprint: \\ San Francisco. 2002 336p.
}

Thiago Guimarães do Sacramento ${ }^{1}$

\begin{abstract}
Resumo: O livro A Handbook of International Peacebuilding: Into the Eye of the Storm é um guia prático produzido por um conjunto de autores com experiências renomadas em Peacebuilding e transformação de conflitos. Atuação dos autores e o escopo da obra é da atuação internacional para a resolução de conflitos, todavia é escrito sob a perspectiva do choque de realidade e culturas. A presente resenha tem como objetivo destacar os elementos práticos apresentados como uma ferramenta para iniciativas de transformação de conflitos em espaços onde ocorre esse choque de culturas, como na amazônia. O livro defende que qualquer iniciativa de transformação de conflitos depende do conhecimento do contexto local e das habilidades que o agente levará a campo e apresenta meios para fomentar as iniciativas locais, propiciar tempo e campo e contribuir para 0 alcance dos objetivos de acordo com as habilidades acionadas.
\end{abstract}

Palavras-chave: Peacebuilding ,diferentes culturas, contexto local, comunidades locais.

\begin{abstract}
The book A Handbook of International Peacebuilding: Into the Eye of the Storm is a practical guide produced by a collection of authors with renowned experiences in peacebuilding and conflict transformation. The authors act and the scope of the work is the international action for conflict resolution, however it is written from the perspective of the clash of reality and cultures. This review aims to highlight the practical elements presented as a tool for conflict transformation initiatives in spaces where this culture clash occurs, as in the Amazon. The book argues that any conflict transformation initiative depends on knowledge of the local context and the skills that the agent will bring to the field and provides means for fostering local initiatives, providing time and field and contributing to the achievement of goals according to skills. triggered.
\end{abstract}

Key Words: Peacebuilding, different cultures, local context, grassroots communities.

\footnotetext{
${ }^{1}$ Mestrando do Programa de Pós-Graduação de Ciência da Sociedade da Universidade Federal do Oeste do Pará
} 


\section{Introdução}

A proposta dos organizadores é reunir um conjunto de autores que tem proeminência no campo de resolução de conflitos no âmbito internacional e traçar, como esforço conjunto, um guia de referência para implementar projetos e iniciativas de transformação de conflitos em outras culturas.

Desde a introdução os editores mostram que a preocupação é com uma abordagem direta sobre o que fazer e quais caminhos seguir. Todavia isso não significa que as contribuições reunidas não possuam profundo caráter teórico, a prática apoiada pelos agentes ao redor do mundo em resolução de conflitos é apoiada e orientada por uma profunda base teórica e é possível observar, em diferentes graus de profundidade definidos pelo tema, a força dessa base.

Ao compor essa resenha, se buscou alcançar dois objetivos distintos: um teórico e outro metodológico. O objetivo teórico é orientado pela necessidade de compreender os elementos apresentados sob a perspectiva de seu aprofundamento e a partir dessa compreensão aplicar em casos concretos os conselhos e práticas apresentados. O objetivo metodológico foi o de apresentar os conselhos e guias de maneira tal que eles possam ser usados em situações que não sejam apenas iniciativas internacionais, mas sim em espaços que choques culturais e de visões de mundo ocorram. Entende-se que a região amazônica é rica em espaços dessa forma, espaços culturais em que a fronteira entre forma de pensar se delineiam e que portanto a aplicação desses princípios em espaços dessa natureza trará profundas contribuições para agentes de transformação de conflitos que operam na amazônia e a partir da amazônia.

O livro tem vinte e nove capítulos divididos em sessões e como em cada capítulo temos um autor ou conjunto de autores diferentes tecemos a discussão capítulo a capítulo e apresentando os momentos em que novas sessões se apresentam e as propostas das novas sessões. Apresentou-se os capítulos divididos em sessões e destacou-se de forma mínima a experiência de atuação dos autores quando se considerou pertinente para a melhor compreensão dos conceitos destacados.

É certo que cada um dos vinte e nove capítulos em si é rico em elementos de discussão e apresentação. A obra é extensa em conceitos e métodos apresentados. 
Entendemos que essa resenha pode auxiliar o aquele que se aproxima da obra em aprofundar o olhar sobre a sessão mais necessária a sua obra e tornar mais efetiva a sua ação em construção de paz e transformação de conflito.

\section{O Convite e o entendimento do quadro geral}

Na primeira parte do livro os organizadores reuniram relatos e falas sobre como conseguir uma ideia geral do conflito e traçar as primeiras iniciativas de contato com o tema. Como desenvolver os primeiros paços na compreensão de um conflito do qual não sabemos nada. Igualmente traz experiências valiosas em compreender de maneira mais profunda conflitos com os quais já nos sentimos familiarizados.

No capítulo primeiro é apresentada a natureza do Peacebuilding é colaborativa. Por isso preciso saber quem demanda a prática. O foco desse saber quem demanda é relacionado ao papel que essa entidade ou organismo desempenha. O conjunto de valores e práticas e sua conexão com o facilitador. Um dos elementos relacionados a entender o quem solicita o atendimento é compreender o contexto de sua presença, quais as relações de poder e os níveis dessas relações (nacional, regional e local) e a natureza de suas manifestações.

Essa compreensão ajudará a entender quem é o responsável pela delimitação do conflito, o que se espera do processo de Peacebuilding e as partes (e seus investimentos de capital pessoal e político) no processo. O elemento político tem uma importância na compreensão do conflito. Afinal a paz é um instrumento político e como tal pode ser influenciada, positiva ou negativamente, pelo capital político dos envolvidos.

No capítulo segundo esposa e esposo ambos os autores dessa seção tem um trabalho extenso em resolução de Conflitos. Susan trabalhou junto às comunidades africanas no período pós-apartheid. É apresentam exemplos e temas práticos para alcançar uma compreensão das expectativas dos que é solicitado. Sugerem a abordagem e levantamento de recursos humanos e financeiros locais bem como na comunidade externa. Reconhecem o protagonismo que os atores locais (comunitários e entidades públicas) internos ao conflito precisam estabelecer para instrumentalizar a realização dos processos de resolução. 
No capítulo terceiro temos a experiência da autora é especialista em atuação sistêmica em tratamento de conflitos. A partir de suas experiências em Chipre e na Bósnia Herzegovina traça um mapa para a operação em rede com os agentes locais. Defende que a articulação sobre experiências anteriores, bem como sobre os atuais atores e agentes seja dividida entre os participantes por meio de contatos e seguindo os princípios de uma cortesia profissional que mostra que todos ali tem o mesmo objetivo. Ainda que o método de Peacebuilding não seja o utilizado na metodologia, a abordagem prática aqui apresentada fala muito mais de como agir em resolução de Conflitos do que a teoria da operação, mas ao fazê-lo traça um modelo teórico de operação. A fala de Lederach no prefácio, sobre a praticidade da proposta, se torna mais forte ao observarmos que os aspetos práticos de um projeto de resolução de Conflitos é que estão sendo abordados.

No capítulo quarto o autor propõe uma resposta a pergunta levantada no titulo que poderia ser sumarizada em: "agir estrategicamente ". Indica que é necessário ter uma compreensão geral do cenário junto aos envolvidos reconhecendo as esferas de liderança maiores, medianas e comunitárias. Posteriormente explicitar o valor que a ação pensada trará aos processos de construção de paz. Destacou a importância de estabelecer um quadro real sobre o que pode ser feito. Após, focar os objetivos nos processos de modificação do ambiente de conflito. Bem como, evitar a duplicação de esforços (a menos que tenham características estratégicas focadas nos processos de transformação) e, por fim, priorizar o fortalecimento dos sistemas intracomunitários e locais.

\section{O Convite e o entendimento do quadro geral}

Na primeira parte do livro os organizadores reuniram relatos e falas sobre como conseguir uma ideia geral do conflito e traçar as primeiras iniciativas de contato com o tema. Como desenvolver os primeiros paços na compreensão de um conflito do qual não sabemos nada. Igualmente traz experiências valiosas em compreender de maneira mais profunda conflitos com os quais já nos sentimos familiarizados.

No capítulo primeiro é apresentada a natureza do Peacebuilding é colaborativa. Por isso preciso saber quem demanda a prática. O foco desse saber quem demanda é relacionado ao papel que essa entidade ou organismo desempenha. O conjunto de 
valores e práticas e sua conexão com o facilitador. Um dos elementos relacionados a entender o quem solicita o atendimento é compreender o contexto de sua presença, quais as relações de poder e os níveis dessas relações (nacional, regional e local) e a natureza de suas manifestações. Essa compreensão ajudará a entender quem é o responsável pela delimitação do conflito, o que se espera do processo de Peacebuilding e as partes (e seus investimentos de capital pessoal e político) no processo.

O elemento político tem uma importância na compreensão do conflito. Afinal a paz é um instrumento político e como tal pode ser influenciada, positiva ou negativamente, pelo capital político dos envolvidos. No capítulo segundo esposa e esposo ambos os autores dessa seção tem um trabalho extenso em resolução de Conflitos. Susan trabaIhou junto às comunidades africanas no período pós-apartheid. É apresentam exemplos e temas práticos para alcançar uma compreensão das expectativas dos que é solicitado. Sugerem a abordagem e levantamento de recursos humanos e financeiros locais bem como na comunidade externa. Reconhecem o protagonismo que os atores locais (comunitários e entidades públicas) internos ao conflito precisam estabelecer para instrumentalizar a realização dos processos de resolução.

No capítulo terceiro temos a experiência da autora é especialista em atuação sistêmica em tratamento de conflitos. A partir de suas experiências em Chipre e na Bósnia Herzegovina traça um mapa para a operação em rede com os agentes locais. Defende que a articulação sobre experiências anteriores, bem como sobre os atuais atores e agentes seja dividida entre os participantes por meio de contatos e seguindo os princípios de uma cortesia profissional que mostra que todos ali tem o mesmo objetivo. Ainda que o método de Peacebuilding não seja o utilizado na metodologia, a abordagem prática aqui apresentada fala muito mais de como agir em resolução de Conflitos do que a teoria da operação, mas ao fazê-lo traça um modelo teórico de operação. A fala de Lederach no prefácio, sobre a praticidade da proposta, se torna mais forte ao observarmos que os aspetos práticos de um projeto de resolução de Conflitos é que estão sendo abordados.

No capítulo quarto o autor propõe uma resposta a pergunta levantada no titulo que poderia ser sumarizada em: "agir estrategicamente ". Indica que é necessário ter uma compreensão geral do cenário junto aos envolvidos reconhecendo as esferas de 
liderança maiores, medianas e comunitárias. Posteriormente explicitar o valor que a ação pensada trará aos processos de construção de paz. Destacou a importância de estabelecer um quadro real sobre o que pode ser feito. Após, focar os objetivos nos processos de modificação do ambiente de conflito. Bem como, evitar a duplicação de esforços (a menos que tenham características estratégicas focadas nos processos de transformação) e, por fim, priorizar o fortalecimento dos sistemas intracomunitários e locais.

\section{O contexto e a geografia do conflito}

Na segunda parte do livro a preocupação dos editores foi em reunir informações sobre o local do conflito, envolvendo: contexto local, elementos culturais, relações de poder e medidas de segurança.

No quinto capítulo o autor busca estabelecer o que deve ser conhecido para compreender o conflito. Destaca inicialmente a necessidade de compreender o papel pessoal do operador do processo de resolução do conflito bem como da organização a que está ligado. Compreender os próprios valores e o lugar de fala da instituição. Após é necessário entender as partes integrantes do conflito e seu contexto, no sentido de se apropriar dos elementos que compõe o conflito e permitir que narrativas, por vezes conflitantes, tenham sua legitimidade reconhecida. Os elementos que precisam ser compreendidos são: as fontes do conflito e como os envolvidos a percebem; Os envolvidos no conflito; os temas do conflito, sejam eles diretos ou indiretos; as táticas de resolução ou enfrentamento que os envolvidos têm utilizado no decorrer do conflito; as mudanças na dinâmica do conflito, quais foram, como foram causadas e outros; o crescimento e ampliação do conflito no decorrer do tempo; os papéis desempenhados pelos envolvidos no conflito, ainda que apenas indiretamente envolvidos; Os resultados possíveis que podem ser esperados do conflito; e por fim, a superação do conflito na fusão das partes envolvidas. É importante perceber o delimitar desses elementos sem olvidar a melhor compreensão virá durante o processo.

No sexto capítulo os autores se foca em destacar a inoperância e necessidade de pesquisa sobre a temática e destaca o cuidado necessário com as fontes e a necessidade de consultar as fontes advindas das diversas visões sobre o conflito. No sétimo 
capítulo o autor traz o questionamento da cultura para a compreensão do conflito. As dimensões que explora são tanto individuais quanto coletivas. Explora a visão de cultura como uma alternativa de compreender e relacionar conceitos. De um ponto de vista prático diferencia coletividades e indivíduos nas suas Manifestações culturais e sugere a compreensão da realidade alheia, da alteridade nas dimensões de conflito. Explora também o exercício necessário de diálogo de categorias desencorajado a tradução de conceitos e apontando para uma troca de significados.

No oitavo capítulo os autores buscaram uma análise prática a questão da cultura. É marcante que toda a obra tem um caráter eminentemente prático, essa é afinal a proposta apresentada desde a sua introdução. Contudo, no capítulo 8 essa busca por praticidade alcança níveis ainda mais profundos que se tornam valiosos como elemento de compreensão do contexto cultural. O autor tece o enfoque para diferentes categorias em conjuntos culturais e em como essas categorias (trabalho, expressão de emoções, eficiência, sucesso, privacidade comunidade, hierarquia, barganha, acordos, intermediação é outras pertinentes a composição do conflito) se relacionam quando se busca a solução do conflito. Assim apresentando um mapa das categorias e suas relações, o que permite uma melhor compreensão da teia de sentidos e categorias necessárias para compreender os elementos do conflito. No nono capítulo o autor discorrer sobre como a religião pode, como elemento cultural, ser um instrumento de conexão entre as partes ou agravamento do conflito. Indica uma postura de respeito mútuo e aconselha a construção de um diálogo de conceitos e valores. No décimo capítulo a autora trabalha com o elemento da segurança em ações de resolução de Conflitos e os riscos agregados a atividade. Inicialmente diferencia o cuidado com a prevenção de acidentes ou doenças dos cuidados com a segurança física e possíveis ameaças por parte de forças envolvidas no conflito. Destaca metodologias de segurança geral para a prevenção de acidentes e doenças e passa a explanar estratégias de proteção da segurança física. Destaca três estratégias principais para o provimento de segurança, quais sejam: estratégias de proteção; visam a proteção através do uso passivo ou ativo de instrumentos ou métodos de proteção, utilizando métodos de evasão e notificação sobre ameaças bem como impedimentos físicos as ameaças. Posteriormente destaca a utilização da metodologia de deterrente; que entende como a contra ameaça que poderia ser identificada como utili- 
zação de guarda armada ou a proteção dos agentes públicos de segurança e por fim a aceitação do risco e a criação de vínculos sociais que permitam desenvolver as estratégias citadas anteriormente de maneira equilibrada. Essa é a metodologia que a autora defende como eficaz para utilizadores do Peacebuilding.

Destaca que através de relações sociais bem desenvolvidas e uma articulação institucional apropriada a força política das organizações a que os facilitadores estejam ligados pode agir como deterrente política e os sistemas sociais e relacionais comunitários como estratégias de notificação de riscos.

No décimo primeiro capítulo sob a perspetiva de ações realizadas em contextos de violência amada ou mesmo em risco de Conflitos violentos os autores apresentam estratégias para reconhecimento e atuação com segurança. Destacam que a segurança é um elemento que não será alcançado com absoluta cer treze, todavia há maiores ou menores riscos envolvidos. Desenvolvem três momentos distintos para a abordagem de situações violentas: 1. Antes de entrar na área de conflito: Nesse estágio a necessidade é de informações sobre a existência de parceiros locais e a compreensão da extensão do conflito, bem como das medidas de segurança disponíveis. 2. No local do conflito: Buscar a orientação da equipe de parceiros locais, e orientar as ações levando em consideração que a presença do facilitador nas áreas de conflito é temporária, enquanto que a dos parceiros e partes envolvidas não tem a mesma características. 3. Após a saída da área de conflito: as ações nesse momento precisam se focar em dar visibilidade a situação de conflito é acompanhar junto aos parceiros o desenvolvimento dos acordos e tensões no local.

\section{Conselhos das áreas de conflito}

Na terceira sessão do livro somos apresentados com o ponto de vista de construtores de paz que fazem parte de áreas de conflito.

A partir do décimo segundo capítulo temos a primeira das óticas que vem da Irlanda do Norte e se foca em elementos de mediação. Todavia sua contribuição valiosa a obra pois apresenta a ótica do conflito. Destaca a necessidade de, em ambientes de conflito, estabelecer uma inequívoca relação com o objeto das ações a serem desem- 
penhadas e a parceria local como instrumento para alcançar tais objetivos. Igualmente, destaca que o trabalho intencionado não pode ser a resolução foi conflito, mas a oportunidade de construir de maneira eficiente uma solução alternativa ao conflito deliberado. Outrossim, destaca a necessidade de construir uma ação responsável ao elemento político e social dos atores envolvidos; quais as metas que as partes esperam, o que se pode construir nos processos de transformação de conflito, os efeitos da negociação no capital político e social das partes, o reconhecimento dos dados causados, a postura não condenatória das ações, devolutiva das ações tomadas e outros.

No décimo terceiro capítulo a autora fala da perspetiva dos esforços de construção de paz na região dos Balcãs. A própria autora resume suas contribuições na frase: "Ouça, para que você consiga ajudar" p. 148. Apresenta suas lições na importância do trabalho continuado e em ligação direta com os atores locais, instrumentalizando o protagonismo desses atores como produtores dos processos de paz. Nesse capítulo a autora destaca como a percepção de que a situação de conflito é compreendida como objeto de pesquisa por parte dos indivíduos envolvidos no processo, é destaca como essa atitude diante da situação de conflito pode inviabilizar o avanço das relações com as lideranças locais e dos processos de construção de paz.

Já no décimo quarto capítulo a autor apresenta a visão vinda do Oriente Médio. Destaca a importância de compreender a realidade local e os processos culturais. Destaca a necessidade de se despir dos valores pessoais e traçar observações precisas sobre as relações de poder nos grupos e atores locais. Igualmente que a ótica de ações deve ser decidida a partir das necessidades da comunidade e sob a perspetiva de valores e conceitos dela. Desaconselha a transposição de medidas sem um detalhado olhar e firma a importância de uma postura de observação precisa e paciente sobre a situação de conflito.

O décimo quinto capítulo traz os relatos da África Ocidental foram trazidos pela contação de história e trouxeram a experiência dos valores e elementos culturais locais utilizando de técnicas de construção de paz como são comumente utilizadas no hemisfério norte. A partir das narrativas das práticas locais, os autores, demonstraram a necessidade de valorização e compreensão do contexto cultural, afinal ?Conflitos tem 
seus sentidos na cultura das pessoas, e é nessas culturas que podem ser encontradas as soluções? p. 168. Portanto, conclui, a construção da paz permite que as soluções internas sejam apoiadas por iniciativas externas, mas nunca direcionadas por estas.

\section{Do Dinheiro à Ética e as necessidades da intervenção}

A quarta sessão da obra traça diálogos e trocas de experiências referentes a financiamentos e resultados esperados, perpassando as questões éticas que esses elementos podem suscitar.

O autor do décimo sexto capítulo aborda os efeitos das estratégias de financiamento sobre a atividade realizada no local e nas ações dos colaboradores locais. Mostra que a aplicação de recursos é muito mais do que apenas o financiamento dos gastos e está imbricada com relações de poder que, se não equilibradas apropriadamente, podem condenar os esforços de construção de paz e limitar severamente sua continuidade.

Suas observações são traçadas a partir dos seguintes elementos: Transparência, como a necessidade de que as estruturas, valores e práticas de financiamento estejam disponíveis a todos os parceiros. Contudo reconhece que sem a agregação dos outros valores a transparência pode causar um maior prejuízo as ações. Inclusão, é apresentada pelo envolvimento dos parceiros locais nas necessidades e construções orçamentárias em cada um dos processos, seja busca de financiamento até prestação de contas. Destaca a importância dessa prática para fomentar a sustentabilidade dos parceiros locais sem a presença das iniciativas vindas dos países do Norte. Responsabilização mútua, a prática da prestação de contas entre os parceiros, mesmo daqueles que são considerados mais politicamente e economicamente mais fortes é fundamental para a construção de uma experiência profunda de crescimento. Nesse ponto, reconhece o autor, reside a dificuldade se lidar com as necessidades de responsabilização financeira de patrocinadores e de instituições financiadoras e sugere que estratégias precisam ser desenvolvidas, como a utilização de instituições intermediárias, ou outras linhas de financiamento serem buscadas. Realidade, como o entendimento das vicissitudes do processo prático, ou seja, diferença de objetivos e metas, choque de práticas socialmente aceitas, possibilidade do alcance de metas. A construção em conjunto desses elementos é indispensável para permitir o sucesso de parcerias e financiamentos e permitir que pro- 
jetos locais tenham um enriquecimento da habilidade técnica administrativa necessária para desenvolver projetos posteriores sem a necessidade de intervenção de parceiros externos como a entidade patronal. Assim, garantindo uma multiplicação de iniciativas e o empoderamento das experiências locais.

Escrito pela perspetiva das organizações financiadoras, o décimo sétimo capítulo, traz um ponto de vista novo sobre as práticas financeiras de um projeto de transformação de Conflitos. Divide essas práticas em dois eixos: a construção de uma relação com os doadores e o planejamento financeiro sólido. Destaca no primeiro ponto a necessidade de ampliar o papel das organizações financiadoras nas atividades a serem realizadas e na medida do possível objetivar uma relação e conhecimento da realidade do projeto. No segundo eixo indica a necessidade de um planejamento real e adequado às atividades, inclusive com a previsão de fundos de emergência e fundos de ação rápida a fim de mostrar planejamento efetivo e segurança da informação apresentada. Destaca que as unidades financiadoras se relacionaram com o projeto na medida de suas semelhanças com o tema e nos limites de suas realidades (reconhece por exemplo que instituições privadas têm um entendimento de privacidade da informação mais estrito do que instituições públicas), mas que quanto mais íntima for essa relação, quer de agências ou indivíduos, melhor será a relação financeira a ser construída e mais ampla as ações tomadas.

No décimo oitavo capítulo os autores discutem a responsabilização pelas atividades realizadas. Apresentam a dimensão responsabilização financeira junto aos organismos financiadores, mas expandem a rede de responsabilização para as entidades parceiras, informantes, comunidade que participou do projeto e desenham a responsabilização como um mosaico que precisa ser centrado a partir da experiência da comunidade onde o trabalho é desenvolvido e a partir daí expandido para os demais setores. Segundo os autores esse trabalho deve ser pensando em torno da comunicação e respostas da comunidade onde o processo de construção de paz se organiza, transparência de motivos e metas, a companhia de informantes que permitam um conhecimento dos elementos culturais onde o trabalho está sendo desenvolvido bem como estabelecer 0 maior contato pessoal com a comunidade, pois assim será possível desenvolver estratégias de responsabilização e informação localmente apropriadas. O trabalho é realizado 
assim em conjunto pois "o sucesso de um trabalho de construção de paz é construir-se para fora do processo" p. 206 e assim permitir que você não seja mais necessário.

No décimo nono capítulo o autor decide explorar as dimensões éticas do trabalho em campo. Observa tem uma perspetiva prática e busca se afastar de construções axiomáticas sobre dilemas éticos, antes, prefere se focar em práticas que estimulem o pensar ético levando em consideração: os valores individuais do facilitador, nesse caso mais proeminentes, posto que os dilemas éticos têm uma ampla dimensão intrapessoal; os valores e práticas culturalmente aceitos pelo grupo e os valores defendidos pelos métodos utilizados. Não se propõe a trazer respostas fechadas, mas sugere refletir, ainda que em campo e durante a atividade, de maneira ativa sobre as repercussões de desses dilemas.

No vigésimo capítulo o autor apresenta a questão dos efeitos deletérios não antecipados dos trabalhos de construção de paz. Inicialmente apresenta a semelhança entre os trabalhos de construção de paz e o trabalho de apoio a vítimas se calamidades e tragédias. Mostra que há semelhanças nos impactos que ambos os trabalhos podem ocasionar principalmente ao se reforçar as estruturas de separação da comunidade e olvidar as estruturas de conexão do grupo e mostra que essas opções equivocadas podem impactar: os efeitos de distribuição, decisões sobre quem incluir e quem excluir podem legitimar certas estruturas sociais; efeitos de mercado, posto que desde a contratação de mão de obra, até de gêneros alimentícios podem reforçar estratégias inapropriadas; efeitos de legitimação, quando a associação é diretamente ligada a um dos grupos envolvidos no conflito; e mesmo a postura diante do conflito, que pode ser observada quando duas iniciativas diferentes buscam a solução do conflito mas não cooperam para tal. Destaca por fim que o reconhecimento desses possíveis efeitos precisam ser antevistos e essa realidade encarada a fim de se construir estruturas para que os elementos de separação sejam minimizados e as oportunidades de conexão sejam melhor aproveitadas.

O vigésimo primeiro capítulo aborda a avaliação como elemento importante do processo de construção de paz. O autor inicialmente destaca a dificuldade de avaliar o trabalho realizado. A Paz buscada pelo processo nem sempre é quantificada e percebível na esfera de tempo útil para o trabalho empregado para alcançá-la. Nesse sentido propõe 
a construção de uma avaliação que leve em consideração os valores locais e os objetivos iniciais e que, a partir dos valores apropriados ao grupo envolvido, perceba as contribuições nesse processo. Defende o autor que a avaliação seja um processo inclusivo e que permita uma real compreensão do trabalho realizado. Todavia, não ignora a utilização da avaliação como ferramenta de aferição de sucesso por parte de agentes financiadoras ou outros atores externos e destaca o perigo que essas ações produzam resultados rasos e que não abarcam a complexidade das ações realizadas. Razão pela qual defende um processo mais amplo de participação nos processos avaliativos. Conclui por fim que apenas um processo avaliativo altamente inclusivo e colaborativo é apropriado para uma atividade tão rigorosa quanto a construção de paz.

\section{A Decisão e seus custos}

A próxima sessão do livro vai abordar o processo da decisão pela participação no processo de construção de paz, seus custos, sua manutenção e os impactos dessa atuação.

No vigésimo segundo capítulo o autor explora as razões e repercussões sobre a decisão final de participar de um processo de construção de paz. O autor fala da perspetiva do trabalho de vários anos e em específico do trabalho realizado na África do Sul que lidou com a desestatização do apartheid. Destaca que a decisão de ir pode ser marcada por características internas relacionadas a um pensamento colonialista e que cada decisão deve levar em consideração os seguintes elementos: Transparência de motivos, as razões devem ser apresentadas de forma inequívoca e através de diálogo é reflexão equacionar os motivos dos grupos envolvidos em um convite dessa natureza; Raízes nos compromissos locais, o contexto local vai apresentar o fundamento das ações atividades propostas e precisa orientar o planejamento e decisões; Valorizar os recursos locais, um dos elementos mais importantes é a realidade local, valorizar os recursos locais é o que vai permitir que uma ação não se enquadre num perfil colonialista e etnocêntrico, valorizar facilitadores locais, expandir a rede de recursos é fomentar o crescimento e protagonismo nos grupos em que o trabalho será realizado; Projeto de longo prazo, as intervenções precisam fazer parte de um processo maior, caso contrário arriscam apenas um impacto limitado, que pode desgastar os atores locais para futuras intervenções; 
Responsabilidade junto às comunidades locais, os setores locais precisam ser atendidos em relação a consideração as duas demandas, isso implica que o processo fortaleça essas comunidades e permita um protagonismo dela no processo de construção de paz. No vigésimo terceiro capítulo, o autor aborda a questão temporal e a dedicação necessária para um trabalho de mediação. Indica que o trabalho a ser realizado precisa ser compreendido de maneira ampla, como parte de um relacionamento e que requer clareza no calendário de atividades propostas e a contraposição do tempo disponível e do papel requisitado a ser desempenhado na atividade. Todos esses elementos precisam instruir inicialmente um cronograma de atividades. Indutor ainda destaca que o papel a desempenhar pode ser de apresentar ideias e fomentar novas formas de ver o conflito, participar de treinamentos ou mesmo planejar treinamentos e implementação. Essas três atividades têm termos de tempo de realização crescente e impactadas pelo caso concreto.

Destaca também o autor a importância da compreensão do tempo para a atividade de mediação e facilitação. Observa que para a realização da atividade é necessário a observação da realidade local e a compreensão do tempo necessário para alcançar os objetivos propostos. Em suma, antes de se comprometer e iniciar um processo de construção de paz é necessário desenvolver ferramentas a fim de mensurado investimento de tempo necessário para a obtenção dos resultados e isso só será possível com a observação da realidade local, através de colaboradores, é o aconselhamento experiente disponível em outros profissionais da área.

No vigésimo quarto capítulo as perspectivas de três autores são trazidas para a questão referente ao custo emocional do trabalho a ser realizado e apresentam a necessidade de buscar uma rede de apoio, em amigos e outros profissionais, entre o grupo trabalhado e fora dele que permitam manter o foco do trabalho desenvolvido. Não perder a dimensão pessoal do custo do trabalho é fundamental para a continuidade do trabalho a ser desempenhado.

\section{Conselhos da experiência}

Numa das últimas sessões da obra a proposta dos organizadores é reunir experiências de veteranos do trabalho na área. 
A experiência de trabalho no contexto africano que em geral recebe intervenções de profissionais do Norte é apresentada, no vigésimo quinto capítulo, pela perspetiva de lições importantes extraídas dessa prática. Inicialmente o autor destaca a necessidade de que o ponto de vista das ações deve ser orientado a partir da realidade do conflito não necessariamente para extingui-lo mas para permitir a convivência das partes. Outrossim, destaca que a construção de paz é um relacionamento que se estabelece com os grupos envolvidos e que isso vai além da técnica, está ligado ao estabelecimento de laços de confiança. Igualmente destaca a necessidade de estabelecer as relações pessoais, com nossos grupos culturais e as relações estabelecidas em campo com a mesma orientação defendida nos processos de transformação de conflito e, por fim, ser conscientes de que as ações desenvolvidas no processo de construção de paz precisam se integrar aos esforços locais e considerar a realidade local, fortalecendo-a e fomentando-a.

No vigésimo sexto capítulo o autor apresenta a visão da construção de paz como um processo relacional que envolve o fortalecimento das iniciativas locais e que requer uma visão orientada em três eixos: uma posição pessoal de ligação ao tema, uma dedicação do tempo para o processo, e aqui, reconhece que o processo de construção de paz é amplo e que não se encerra num determinado cronograma, mas que necessita de uma dedicação prioritária em relação ao tempo para funcionar, e por fim o eixo do trabalho local e a busca do crescimento de expressões próprias de resolução aliadas a responsabilidade local da ação. Esses três eixos podem desenvolver diversas ações mas se tornam o elemento de princípio que guia as ações.

A autora, no vigésimo sétimo capítulo, destaca o amplo espectro de sua experiência a partir da manutenção do vigor no trabalho. Preconiza que é necessário olhar o futuro, é necessário incluir grupos que são marginalizados nos processos em geral (muIheres e crianças) e é necessário manter a perseverança. A esperança é a ferramenta que pode transformar as realidades de um conflito.

O vigésimo oitavo capítulo é a transcrição de uma entrevista realizada. Nele ps entrevistadores direcionam as perguntas para ps elementos de psicológicos de fortalecimento dos facilitadores do processo. Pensar a construção de paz a partir do custo emocional e como resposta a este custo encontrou por parte do entrevistado uma resposta 
comum em vários conselhos anteriores: desenvolva relacionamentos, eles são sua força e sua maior vantagem; escute onde você está para não se perder; tenha consciência do que você pode fazer para não se frustrar.

\section{Conclusões finais}

No vigésimo nono e último capítulo os organizadores tomam a responsabilidade de sintetizar o que foi produzido. Destacam dentre outros elementos, a importância do trabalho local e a necessidade de parcerias, de estabelecer relações, de desenvolver métodos de responsabilização e acompanhamento para que mais integrantes do processo de construção de paz possam participar (sejam financiadores até à comunidade local), conhecer os papéis a desempenhar e os próprios limites e assim por diante. Fazem isso através de princípios com aplicações práticas: conheça a você mesmo; tenha relacionamentos transparentes; aprenda sobre o contexto; aconselhe-se, aconselhe-se e aconselhe-se; seja realista sobre o que você pode oferecer; seja humilde, principalmente em saber os seus limites; e seja ousado, principalmente ao perguntar, ao se relacionar, se comprometer. Em suma apresentam os elementos práticos necessários a para o trabalho em outras culturas. Por isso o valor da obra se destaca, pois apresenta a prática da construção de paz no encontro de modos diferentes de cultura, na fronteira, assim também é a realidade amazônica, um encontro de fronteiras e modos de viver, cada um dos guias práticos, não regras, oferecidos pode ser aplicado a realidade de conflitos na Amazônia onde se chocam modos de viver, manifestações culturais e esperanças. O Conselho final aos facilitadores também é válido diante desse desafio:"pratiquem a justiça, amem a misericórdia e andem humildemente. Mas, antes de mais nada, continuem andando".

\section{Referências}

